\section{A gripe espanhola em Sorocaba e o caso da fábrica Santa Rosália, 1918: contribuições da história local ao estudo das epidemias no Brasil}

\section{Spanish Flu in Sorocaba and the case of the Santa Rosália factory, 1918: local history contributions to the study of epidemics in Brazil}

João Paulo Dall'Ava

Historiador, mestre pelo Departamento de Medicina Preventiva/ Faculdade de Medicina/Universidade de São Paulo (FMUSP).

Avenida Doutor Arnaldo Vieira de Carvalho, 455, 2 andar 01246-903 - São Paulo - SP- Brasil

jpdallava@yahoo.com.br

\section{André Mota}

Professor, Departamento de Medicina Preventiva/FMUSP; coordenador do Museu Histórico Prof. Carlos da Silva Lacaz/FMUSP. Avenida Doutor Arnaldo Vieira de Carvalho, 455, $2^{\circ}$ andar 01246-903 - São Paulo - SP-Brasil

a.mota@fm.usp.br
DALL'AVA, João Paulo; MOTA, André. A gripe espanhola em Sorocaba e o caso da Fábrica Santa Rosália, 1918: contribuições da história local ao estudo das epidemias no Brasil. História, Ciências, Saúde-Manguinhos, Rio de Janeiro, v.24, n.2, abr.-jun. 2017, p.429-446.

\section{Resumo}

Investigam-se as tensões surgidas durante a epidemia de gripe espanhola na cidade de Sorocaba, ocorrida entre os meses de outubro e dezembro de 1918. São utilizadas como fontes privilegiadas e inéditas as narrativas repercutidas pela imprensa local, tomando como estudo de caso a fábrica Santa Rosália, envolvida na recusa de seu proprietário em manter a interrupção dos trabalhos no auge da crise epidêmica, mesmo sob pedidos do poder municipal. Busca-se contribuir com os estudos sobre as epidemias nos municípios do interior do país, ressaltando as colaborações da história local às investigações sobre a história das doenças no Brasil.

Palavras-chave: gripe espanhola; epidemia; história local; saúde pública.

Abstract

An investigation is presented of the tensions that emerged during the Spanish flu epidemic in the city of Sorocaba, Brazil, between October and December 1918. It draws on previously unused primary sources, namely the narratives contained in the local press, taking the Santa Rosália factory as a case study, particularly its owner's refusal to maintain the work stoppage at the height of the epidemic, even when requested to by the municipal authority. This research contributes to the study of epidemics in Brazil's inland municipalities, emphasizing how local history can contribute to investigations of the history of disease in the country.

Keywords: Spanish flu; epidemic; local history; public health. 
$\mathrm{O}$ primeiro contato de brasileiros com a gripe espanhola, que irrompeu como epidemia a partir de agosto de 1918, teria se dado por intermédio dos integrantes da missão médico-militar que atuou nos últimos meses da Primeira Guerra Mundial. Ao aportar em Dakar, no Senegal francês, a maior parte desse grupo teria sido contaminada pela pandemia, que já infestava a cidade.

Acredita-se que a moléstia tenha sido trazida ao território nacional por um navio inglês, o Demerara, que passou pelos portos de Recife, Salvador e Rio de Janeiro. Em meados de setembro, essas cidades portuárias já estavam infestadas (Bertolli Filho, 2003, p.73-74; Bertucci, 2003, p.93-96; Brito, 1997, p.17-19). Em outubro, a cidade de São Paulo e alguns municípios do interior já estavam impactados com o mal.

Alguns estudos sobre a propagação da gripe espanhola nas principais capitais brasileiras fornecem informações importantes sobre o desenvolvimento da doença e as atitudes da população e das autoridades locais em relação ao seu combate. Exemplarmente em Salvador, durante a epidemia, as disputas entre facções políticas no estado da Bahia, a insalubridade da capital e a precariedade dos serviços de saúde locais tornaram-se mais evidentes (Souza, 2005, p.74-81).

Nesse sentido, as querelas políticas influenciaram o modo como as informações sobre a doença eram transmitidas à população, já que, inicialmente, as autoridades e seus correspondentes órgãos de imprensa insistiam na benignidade da gripe, além de não divulgar o número total de óbitos, enquanto os jornais de oposição, em meio a críticas às autoridades locais, empenhavam-se em divulgar a maior quantidade possível de informações sobre a propagação da doença (Souza, 2005, p.82-85).

No Rio de Janeiro, as autoridades, a princípio, emitiam opiniões imprecisas sobre a doença, demonstrando desconhecimento. Também transparecia certo otimismo em seus discursos, pois a "opinião médica endossava o pressuposto de que a doença se transmudara no Brasil sob a influência do clima tropical, o qual teria produzido um efeito positivo, e surpreendente, ao minimizar a virulência atuante em outros países" (Brito, 1997, p.19).

Para conterem-se os ânimos, portanto, reforçava-se o caráter benigno da gripe, mas as primeiras mortes encerraram o clima otimista e iniciaram uma série de debates entre médicos e leigos sobre a origem e a transmissão da doença (Brito, 1997).

Outro aspecto importante seria o problema da "exposição pública de cadáveres", uma das principais questões enfrentadas pelas autoridades cariocas durante a epidemia. Isso porque não havia uma estrutura sanitária preparada para desempenhar os serviços funerários necessários ao atendimento do grande número de óbitos causados pela gripe, sendo que muitos corpos ficavam expostos nas ruas à espera de sepultamento ou amontoados, dentro de caixões ou não, em caminhões que faziam o transporte para os cemitérios (Brito, 1997, p.24).

Sobre a propagação da gripe espanhola na cidade de São Paulo, Claudio Bertolli Filho (2003) reconstituiu a "geografia da gripe" e mostrou sua "ilusão democrática", identificando os maiores pontos de infecção entre os diversos distritos do município de São Paulo e desmentindo, assim, alguns relatos que afirmavam que a epidemia atingiu da mesma maneira as classes privilegiadas e as menos favorecidas. Segundo o autor, a 
doença, ainda hoje, "é vista como uma enfermidade que se propaga independentemente das condições de vida específicas das classes sociais, pois é entendida como uma espécie de 'acidente' ligado mais à sorte ou ao azar individual do que a qualquer outro elemento determinante" (Bertolli Filho, 2003, p.89; destaque no original).

Outro ponto destacado foi o pânico reinante na cidade durante a epidemia e como ele afetou a vida das pessoas. Entre 1917 e meados de 1918, além das notícias sobre a Grande Guerra que chegavam a São Paulo, mudanças climáticas e pragas de insetos afetaram a agricultura, gerando grande carestia de alimentos. Esses eventos contribuíram para um sentimento de medo coletivo que, reforçado pela convivência constante com a morte, desencadeou atitudes como o isolamento total de pessoas em suas casas, suicídios e delírios, comuns no auge da crise sanitária (Bertolli Filho, 2003, p.249). Esse tema também foi explorado por Teixeira (1993, p.30), ao investigar o modo como as populações das cidades do Rio de Janeiro e de São Paulo enfrentaram o medo causado pela difusão da epidemia e pelo vertiginoso aumento do número de óbitos.

Nessa direção, cabe atentar para a crise vivida pela medicina oficial, ao mesmo tempo que formas alternativas de cura se difundiam entre a população. Apesar da convivência entre as medicinas alopática e homeopática no combate à influenza, ambos os segmentos redundaram em fracasso, o que inclinou o povo a recorrer à medicina popular em busca de cura:

Limão (com ou sem pinga), canela, folhas de eucalipto, cebola e alho. Produtos 'caseiros' que mereceram inclusive a atenção das autoridades governamentais e sanitárias, alguns, como a canela, acabaram industrializados e diversos foram largamente empregados na tentativa de debelar o padecimento dos gripados (Bertucci, 2003, p.150).

Diante dos estudos efetivados até aqui, as experiências de certas localidades diante da gripe espanhola ainda se encontram dispersas e pouco conhecidas. Esse é o caso de seu impacto pelas cidades do interior do estado de São Paulo e suas formas de recepção e combate. Nesse sentido, o estudo apresentado tem como objetivo investigar as tensões surgidas durante a epidemia na cidade de Sorocaba, entre outubro e dezembro de 1918, utilizando como fonte privilegiada e inédita a sua repercussão pela imprensa local. Para tanto, é enfocado o caso da fábrica Santa Rosália e a recusa de seu proprietário em manter a interrupção dos trabalhos no auge da crise epidêmica, mesmo sob pedidos do poder municipal, evidenciando as condições específicas de uma cidade do interior paulista que passava por importantes transformações econômicas e sociais.

A construção da fábrica Santa Rosália em 1890 e de sua vila operária foi obra da sociedade entre o alemão George Oeterer e seu genro Frank Speers. O estabelecimento industrial foi um dos mais importantes de Sorocaba, situando-se, assim, como sua vila operária, fora do perímetro urbano da cidade (Bonadio, 2004, p.221).

Localizada a aproximadamente cem quilômetros da cidade de São Paulo, Sorocaba tornouse o principal posto de arrecadação de impostos sobre o trânsito de animais entre a região Sul e o planalto paulista, com a instalação do Registro de Animais, em 1750. Tornou-se, também, importante centro redistribuidor de animais para transporte ao longo do século XIX, apresentando um expressivo crescimento de sua indústria têxtil a partir dos primeiros anos do século XX. 
Evidenciando-se as especificidades da cidade de Sorocaba no contexto da epidemia especialmente o episódio envolvendo a fábrica Santa Rosália -, busca-se apresentar um estudo de caso que possa contribuir para uma melhor compreensão sobre o impacto da gripe espanhola nos municípios do interior do país. Essas localidades, muitas vezes, não contavam com a mesma estrutura médico-sanitária das capitais - que, na ocasião, em muitos casos, também eram atacadas pela epidemia -, e, portanto, tiveram que se valer dos recursos locais no enfrentamento da crise epidêmica. Pretende-se, também, ressaltar as contribuições da história local às investigações sobre a história das epidemias no Brasil para além de suas capitais.

\section{Saúde pública e sanitarismo em Sorocaba na Primeira República}

Ao longo da Primeira República (1889-1930), aumentaram as atribuições do poder central nos assuntos relacionados à saúde pública. Nesse momento os problemas sanitários passariam a ser compreendidos como questão nacional, devido à preocupação de determinados grupos com a maior interdependência social e territorial entre as diversas regiões do país, resultando no desenvolvimento de políticas públicas nacionais de saúde, em sua maioria, voltadas ao combate das endemias rurais. Esse processo se tornou mais evidente durante as décadas de 1910 e 1920, período denominado por Hochman (1998, p.87-88) de "era do saneamento", quando também teria ocorrido uma ampliação da penetração do Estado na sociedade e no território brasileiros.

Apesar do federalismo vigente na organização político-administrativa do país, os estados brasileiros, por insuficiência de recursos, eram obrigados a apelar para intervenção do poder federal a fim de solucionar os problemas relacionados às questões de saúde pública. A "exceção" seria o estado de São Paulo, que com recursos próprios conseguiria colocar em prática parte das medidas de saúde pública e saneamento em seu território, garantindo sua autonomia (Hochman, 1998).

O contexto em que ocorreu a consolidação de São Paulo como centro científico e tecnológico de relevância para o país, entre o final do século XIX e as primeiras décadas do XX, marcou também um forte processo de intervenção de suas instituições médico-sanitárias sobre os municípios interioranos, os chamados "sertões", para, além de combater as doenças, levar a "civilização" a esses lugares. Fortemente marcado por uma ideologia de construção nacional, esse movimento abandonou o determinismo racial - muito influente entre alguns intelectuais que buscavam explicar as razões do "atraso" brasileiro -, buscando o progresso por meio do saneamento rural (Castro Santos, 1985, p.193-195).

É nesse contexto que se busca compreender o combate às epidemias em Sorocaba e suas particularidades. Desse modo, considerando as especificidades locais, evita-se o risco de generalizações teóricas:

A necessidade de modelos externos, que se transformam em paradigmas, acaba criando uma visão deturpada do objeto de estudo: vê-se não o real, mas o que o modelo prevê, forçando explicações e criando parâmetros ilusórios com outros tantos fenômenos... No caso do estudo de cidades, tal situação leva ao risco da perda do específico, do objeto em si, na deformação do material disponível. A tendência é procurar o que é o geral em 
todos os estudos definidos como modelos paradigmáticos, confirmando-os, reforçando-os e não debatendo outras possibilidades (Glezer, 2007, p.156).

O processo de urbanização e industrialização pelo qual passava Sorocaba na virada do século XIX para o XX influenciou as medidas implementadas pelas autoridades locais em relação às questões sanitárias e de saúde pública. Em 1896, o intendente municipal de Sorocaba, em relatório publicado no jornal O 15 de Novembro, referia-se à importância da higiene para o bem-estar da população e para a saúde pública. Apesar de apontar algumas necessidades como "o problema da remoção do lixo, das águas servidas, ... além do saneamento do ribeirão do Supiriri, da desinfecção das latrinas com cal virgem", a autoridade afirmava: "Sorocaba, a higienópolis paulista, não precisa de muito para que seja garantida a conservação do estado sanitário que graças a Deus temos tido a felicidade de gozar" (Carvalho, 2008, p.106).

Com a criação de um Serviço de Limpeza Pública em Sorocaba, no início de 1897, evidenciaram-se as permanentes pendências nesse setor. Os fatos se deram no momento em que se promovia o projeto estadual de São Paulo para legislar e impor ações de controle sanitário aos municípios por meio do Serviço Sanitário. A resistência dos municípios às intervenções sanitárias estaduais muitas vezes se baseava no intuito de beneficiar empresários locais com "serviços que pudessem ser privatizados como os de varrição, recolhimento e destinação das águas e do lixo doméstico" (Mota, 2006, p.9).

Os debates na imprensa sorocabana sobre a criação do serviço, que seria concedido a um empresário local, colocavam, de um lado, o jornal oposicionista $A$ Voz do Povo, contrário à forma como seriam realizados os trabalhos - inclusive exigindo por meio de um abaixo-assinado e por uma representação formal dirigida à Câmara, a revogação da lei que regulamentava a limpeza pública municipal -, e do outro, o situacionista $O 15$ de Novembro, favorável à empreitada. Esses embates apontavam a dificuldade das questões sanitárias "numa cidade que, paulatinamente, se industrializava, urbanizava e, ao mesmo tempo, identificava uma série de demandas, principalmente as correspondentes à organização e higienização desses espaços" (Mota, 2006, p.9-10).

Criada a Empresa de Limpeza Pública, em moldes privados, como pretendia a Câmara, começam os trabalhos de varrição e remoção de lixo, em meados de janeiro. Entretanto, o serviço atendia apenas a região central da cidade e ainda de forma precária:

Essa tentativa de assegurar ao município o poder de controlar as ações sanitárias tinha, porém, limites visíveis. Primeiramente, o Serviço de Limpeza Pública assumiu posturas que redundaram em respostas isoladas, com um projeto de varrição e remoção do lixo, apenas, das áreas centrais da cidade. Somava-se ao fato a ausência de um sistema de esgotos, de canalização de águas e mesmo de fiscalização das casas e dos cuidados exigidos nos quintais como o uso da cal e da creolina (Mota, 2006, p.10).

Interessante notar que os embates entre os jornais envolvidos na questão da limpeza pública se tornaram cada vez mais acirrados à medida que a empresa encarregada do serviço iniciava os trabalhos. A respeito do abaixo-assinado exigindo a revogação da lei sobre a limpeza pública, o jornal O 15 de Novembro (Seção Livre, 21 jan. 1897, p.2) publica uma série de protestos por 
parte de pessoas que tiveram seus nomes colocados no documento sem autorização, ou que alegaram terem sido iludidas ao fazê-lo.

Por outro lado, o jornal $A$ Voz do Povo afirmava que a maioria dos que se dirigiram à imprensa para informar que tinham sido enganados ou que não haviam dado autorização para colocação de seus nomes no abaixo-assinado teriam sido constrangidos a fazê-lo. Como exemplo, mencionava um caso em que um analfabeto teria sofrido ameaças que o levaram a declarar por meio da imprensa que seu nome constava no abaixo-assinado sem sua autorização (Seção Livre, 22 jan. 1897, p.2).

À medida que as discussões e acusações mútuas por parte dos jornais aumentavam, a contenda tomou uma proporção tamanha que fez com que o editor do jornal A Voz do Povo fosse obrigado a se mudar de Sorocaba, passando a publicar seu periódico no município de Tatuí - próximo a Sorocaba -, permanecendo em atividade até 1898 (Imprensa..., 2007, p.83).

Além dos problemas de saneamento, a cidade foi vítima de dois surtos de febre amarela: o primeiro em 1897, e o segundo em 1900. Nesse contexto, a estrutura sanitária municipal, que não dispunha dos meios necessários ao combate eficaz à propagação da epidemia, submeteu-se à intervenção do recém-criado Serviço Sanitário do Estado de São Paulo - em atividade desde 1892 -, fato que provocou uma série de discussões e embates políticos locais.

Desse modo, identificam-se os embates gerados entre o poder estadual, representado pelas intervenções realizadas pelo Serviço Sanitário, e o poder local, representado pela resistência das elites municipais - na maioria das vezes movida por interesses políticos e econômicos - a essas "intromissões" (Mota, Baddini, 2011, p.177).

Verifica-se uma provável estagnação da economia sorocabana durante o último surto de febre amarela, além de um êxodo populacional. Portanto, os prejuízos teriam sido consideráveis, pois, "além das vítimas, houve a quase total paralisação das atividades comerciais e o fim da boa fama que gozava o clima da cidade, como lugar aprazível para visita e restabelecimento da saúde" (Carvalho, 2004, p.206).

Por meio das páginas da imprensa e dos relatos de memorialistas, pode-se concluir que o impacto causado pela febre amarela em Sorocaba foi uma experiência traumática sem precedentes para a cidade (Dall'Ava, 2012). O grande número de mortos, a paralisação da cidade e o pânico reinante no momento das epidemias - principalmente durante a de 1900 - ficaram marcados na memória coletiva local. Durante os primeiros anos do século $\mathrm{XX}$, caracterizados pela recuperação da economia local, bastante afetada pelas epidemias, a cidade intensificou seu crescimento urbano e populacional, apostando na industrialização como promotora do "progresso sorocabano". Entretanto, no momento em que a identidade da "Manchester Paulista" - modo como a imprensa local passou a se referir a Sorocaba nesse período - se consolidava, e a preocupação com as greves operárias e os conflitos sociais se sobrepunha ao medo das doenças, um novo flagelo atingiu a cidade. Era a epidemia de gripe espanhola, em 1918. 


\section{A gripe espanhola em Sorocaba}

Sorocaba vinha apresentando mudanças significativas desde o final do século XIX, marcadas pelo crescimento de seu núcleo urbano, aumento da população e uma relativa diversificação das atividades econômicas. Após a interrupção causada pela febre amarela, essas mudanças se intensificaram nos primeiros anos do século XX, como vinha ocorrendo em outras cidades do interior de São Paulo. A população sorocabana saltou de 17.068 habitantes, em 1890, para 39.586, em 1920, de acordo com os números do censo demográfico (Pinto Jr., 2003, p.64).

Esse contexto representou um momento decisivo, em que, por meio da imprensa, setores da elite sorocabana pretendiam ao mesmo tempo se distanciar da imagem de cidade tropeira representada pelas feiras e pelo comércio de animais, responsáveis por grande parte da acumulação de capitais em Sorocaba ao longo do século XIX - e superar definitivamente as epidemias de febre amarela.

Portanto, nesse momento, uma das principais preocupações que constavam nos jornais era com uma mão de obra disciplinada, pois nesse contexto de progresso, eram necessários trabalhadores preparados para a labuta diária e que não prejudicassem seu desempenho com maus hábitos. O trabalho, auxiliado pela técnica e pela ciência, era o meio fundamental para o progresso, ideal tão almejado pelo pensamento burguês nesse início de século. Sendo assim, buscava-se nos símbolos ligados à indústria a afirmação de uma cidade moderna, civilizada e progressista:

a Manchester Paulista constitui um símbolo de superação de uma sociedade, como tantas outras no Brasil, que enfrentou problemas de transformação, foi dependente de uma produção de riqueza agrícola ou comercial, lutou contra doenças endêmicas e que, finalmente, venceu o atraso representado pelo passado e assegurou um posto entre as cidades civilizadas e modernas do país (Pinto Jr., 2003, p.61).

Entretanto, contrapondo-se ao otimismo das elites em relação às fábricas, Sorocaba abrigava um operariado estruturado e atuante. Desde o fim do século XIX, os trabalhadores das fábricas e oficinas da cidade passaram a se organizar em associações mutualistas, muitas delas criadas por imigrantes. Entre elas constavam a Sociedade Operária Italiana Umberto I, de 1885; a Sociedade Beneficente e Protetora dos Chapeleiros, criada em 1890; a Sociedade Italiana de Beneficência e Mútuo Socorro e a Sociedade Beneficente dos Empregados da Companhia União Sorocabana e Ituana, ambas criadas em 1896 (Bonadio, 2004, p.251-252).

A partir da década de 1910, intensificou-se a mobilização do operariado sorocabano, que vinha se desenvolvendo desde o início do século. As condições de vida e de trabalho se deterioraram gravemente, fazendo crescer o descontentamento e dando início a um período de grandes greves, entre 1917 e 1919:

Nos primeiros meses de 1917, apareceram diversos artigos na imprensa sobre a situação do operariado e da carestia de vida. Os artigos tratavam dos problemas de maneira geral e também, especificamente para Sorocaba. Os assuntos eram: higiene no trabalho, inspetoria do trabalho, trabalho feminino e de menores. A situação geral da classe operária estava precária, o descontentamento crescia (Araújo Neto, 2005, p.122).

Além do crescente processo de organização que vinha sendo promovido pelos operários e que preocupava as elites locais, a década de 1910 também foi marcada por uma série de 
medidas restritivas e segregacionistas, tomadas pelas autoridades públicas sorocabanas contra determinados setores da população. A repressão contra manifestações culturais e práticas de cura populares, principalmente caboclas e afro-brasileiras, tornou-se constante. Em 1913, João de Camargo, um conhecido taumaturgo da cidade, foi preso acusado de curandeirismo:

João de Camargo foi o mais conhecido de todos, mas outros praticantes dessas formas de cura e sociabilidades também seriam perseguidos pelas autoridades públicas da cidade, acusados de curandeiros e feiticeiros com seus variados sortilégios. Tais práticas que perpassavam a sociedade sorocabana das primeiras décadas do século XX deveriam ser perseguidas e criminalizadas, pois não eram condizentes com a imagem de uma moderna cidade industrial, a Manchester do interior do estado de São Paulo (Carvalho, 2008, p.231).

A repressão à medicina popular, além de evidenciar aspectos de uma herança escravista, demonstrou também um momento em que a medicina oficial vinha tentando se sobrepor às práticas alternativas de cura. Portanto, é nesse contexto de promoção da cidade industrial, moderna e salubre, e da consolidação da medicina oficial como prática de cura dominante que a epidemia de gripe espanhola chegou a Sorocaba, ameaçando o desenvolvimento da Manchester Paulista.

Não existem estudos historiográficos sobre a epidemia de gripe espanhola em Sorocaba, e a maioria das pesquisas que abarcam o período de sua ocorrência na cidade nem cita o episódio. O que se encontra sobre esse acontecimento são relatos memorialísticos publicados na imprensa, centrados quase sempre na atuação dos médicos no combate à epidemia.

Exemplarmente, em um artigo no jornal Cruzeiro do Sul, de 25 de dezembro de 1964, escrito pelo memorialista local Aluísio de Almeida, intitulado "Prof. Dr. José Ribeiro Neto, Sorocabano Benemérito", foi feita uma homenagem a um dos médicos que participaram do combate à epidemia de gripe espanhola em Sorocaba. Referindo-se ao episódio, assim se inicia o texto:

Resumindo a crônica moderna de Sorocaba para o terceiro tomo de minha pequena História, deparei com a Gripe Espanhola de 1918. Médicos, prefeito, farmacêuticos, hospitais improvisados, escoteiros, sim, escoteiros de bicicleta levando receitas aviadas até as casas dos doentes, fábricas paradas, um Deus nos acuda! (Almeida, 25 dez. 1964, p.4).

Ribeiro Neto, membro da Sociedade de Medicina e Cirurgia de São Paulo, em discurso realizado no Gabinete de Leitura Sorocabano, em 1938, fez um breve relato do acontecimento. De acordo com ele, o também médico Álvaro Soares, tendo sido “campeão decidido no combate de epidemias anteriormente surgidas em Sorocaba, ainda se fizera notar por valiosos serviços prestados à população quando aqui surgiu a pandemia gripal de 1918" (Ribeiro Neto, 27 nov. 1938). Segundo Ribeiro Neto (p.3), a epidemia

Começou pelo bairro da fábrica Santa Rosália. O sr. Eduardo Pirajá, ilustre clínico da cidade, hoje em São Paulo, em princípios de Novembro, andava às voltas com os primeiros casos. Mais de espaço, por toda a parte era assinalada a sua presença, até nos bairros distantes.... Caem as vítimas, algumas de projeção social na cidade.

A menção ao início da epidemia no bairro da fábrica Santa Rosália é sintomática, mesmo não sendo possível confirmar essa afirmação, pois o local parece ter sido uma das regiões mais afetadas da cidade, trazendo indícios que contribuem para a compreensão da complexidade da epidemia em Sorocaba. 
Em seguida, foram citados os principais médicos que se dedicaram ao atendimento das vítimas. Eram eles: Álvaro Cesar da Cunha Soares, João de Almeida Tavares, Odilon Goulart, Gentil Fontes, Eduardo Augusto Pirajá, José Ribeiro Neto, Luiz de Almeida e Heitor Maurano. Todos atuavam na cidade, sendo alguns sorocabanos de nascimento - como Álvaro Soares e José Ribeiro Neto. A maior parte atendia na Santa Casa de Misericórdia e em consultórios localizados na rua Doutor Álvaro Soares, como Luiz de Almeida, José Ribeiro Neto e Odilon Goulart (Anúncios, 3 jan. 1919, p.2). Eduardo Pirajá era médico particular da fábrica Santa Rosália e atendia exclusivamente os operários e moradores da vila operária pertencente à fábrica.

O destaque dado no relato de Ribeiro Neto à participação dos médicos locais no combate à gripe espanhola em Sorocaba mostra a importância que a corporação adquiriu naquele momento. Ao longo do século XIX, a corporação médica deu início a um processo de institucionalização e organização profissional. A partir de 1830, começou a se constituir uma elite médica na corte do Rio de Janeiro que buscou exercer o controle sobre a atividade profissional, o ensino e a produção de conhecimento. Quanto à trajetória profissional desses médicos, a ocupação de cargos públicos e honoríficos, a ligação com instituições militares de saúde e a dedicação à atividade política foram as atividades predominantes (Ferreira, 1994, p.63-64). No fim do século, ocorreram as reformas no ensino médico que trouxeram grandes mudanças para a Faculdade de Medicina e Cirurgia do Rio de Janeiro, inclusive incorporando aspectos da chamada "medicina experimental" (Edler, 1992).

Em São Paulo, a década de 1890 marcou um momento de discussões em torno da medicina e da corporação médica:

A busca por outra identidade profissional marca a nova etapa de organização do mundo médico que, sob a égide da República, se instalava em São Paulo. Nessa busca, enfatizavam-se o enunciado científico, o treinamento especializado, a produção de conhecimento experimental e a institucionalização de novos espaços para a medicina (Silva, 2014, p.86).

Nesse contexto, desenvolvia-se um projeto médico-sanitário idealizado pelo estado de São Paulo, a "locomotiva sanitária do país", que levaria "o interior e sua capital ao paraíso da higiene e da elevação da raça paulista. Era a 'medicina bandeirante' em ação" (Mota, 2005, p.47; destaque no original).

Nesse sentido, propunha-se um aumento das atribuições concedidas aos médicos em conjunto com uma formação profissional mais ampla, nos limites entre a ciência, a técnica, a filosofia, a política e a administração:

O saber médico-científico buscava estabelecer maior amplitude a partir de espaços organizados para isso: sociedade, revistas, hospitais, faculdades. Em todos esses lócus de acesso privilegiado ao médico formado as constantes disputas já não falam contra uma medicina popular e informal, mas se estabelecem em busca de harmonia de pontos de vista, de hegemonia de grupos, de reconhecimento social e de ampliação de conhecimentos específicos (Silva, 2012, p.97).

Nos municípios do interior, como Sorocaba, predominava no momento da epidemia de gripe espanhola a prática profissional conhecida como medicina liberal (Schraiber, 1993), 
marcada pelo trabalho individual do médico e pelo atendimento predominantemente em consultório particular:

Entre o médico e o paciente não existia qualquer mediação burocrática. A autonomia técnica e econômica estava garantida em sua plenitude. A relação era individualizada e direta. O trabalho coletivo ou de equipe era incompatível com este tipo de perfil. Por esta razão, os atributos individuais do profissional foram ressaltados em detrimento de elementos próprios ao trabalho em equipe, submetido a procedimentos racionais ou burocráticos (Pereira Neto, 2001, p.45).

As notícias sobre a epidemia de gripe espanhola no Rio de Janeiro e em São Paulo começaram a ocupar as páginas da imprensa sorocabana no final de setembro de 1918. Em fins de outubro, foram noticiados os primeiros casos da enfermidade em Sorocaba, quando, segundo o jornal Cruzeiro do Sul, contavam-se os enfermos em "algumas dezenas", embora a imprensa negasse a epidemia e sempre insistisse na benignidade dos casos:

Os casos de influenza se contam por dezenas na nossa cidade. São todos muito benignos, mas isso não quer dizer que os conselhos dados pelo Serviço Sanitário, a fim de evitar a enfermidade, devam ser desprezados. Sabemos que a prefeitura municipal está apta para enfrentar uma possível epidemia da gripe. Nesse sentido, foram tomadas importantes medidas. Por sua vez, a polícia agirá como deve para obstar que a influenza assuma aqui proporções calamitosas (A influenza..., 24 out. 1918).

Sob a ameaça de uma epidemia, as autoridades municipais se apressaram em tomar providências como a proibição da venda de "sorvetes e gelados", de "frutas depois das 10 até as 17 horas" e para os "clubs de football", a suspensão de seus "matches e trainings" (A influenza..., 24 out. 1918). Além disso, as autoridades eclesiásticas também iniciaram uma mobilização contra a enfermidade:

Para chamar as bênçãos de Deus, afastando o perigo de uma epidemia que, tendo embora caráter benigno e pouco assustador, pode todavia agravar-se de um momento para outro, manda S. Ex.a. Rev.ma. o Sr. Arcebispo Metropolitano que todos os sacerdotes deem na missa, de acordo com as prescrições litúrgicas, a oração da missa provitanda mortalitate, vel tempore pestilentiae, e que imediatamente depois da missa principal em cada igreja, recitem com o povo a ladainha de Todos dos Santos e as orações respectivas (A epidemia, 26 out. 1918).

Entretanto, apesar dos esforços das autoridades, no dia 6 de novembro já havia aproximadamente 671 casos da doença notificados pelos médicos, e a imprensa falava pela primeira vez em casos fatais:

O estado sanitário da cidade piora dia a dia com o acréscimo diário de centenas de gripados. Anteontem, só os casos verificados pelos srs. médicos atingiram o número de 214! Os casos fatais têm sido relativamente poucos, pois andam por uma dúzia até agora, quando é certo há quinze dias, já que a cidade foi invadida pela influenza (A influenza, 6 nov. 1918).

Durante o mês de novembro, a epidemia se intensificou. No dia 10, anunciava-se: "Há talvez mais de três mil gripados na cidade, e a mortalidade anda por 7 a 8 casos diários" (A influenza, 10 nov. 1918). O aumento dos óbitos em decorrência do impacto da 
epidemia elevou muito o número de enterros, fato que teria levado o jornal acima referido a noticiar: "os sentenciados da cadeia local estão trabalhando na abertura de valas no cemitério" (p.2). Posteriormente, o jornal afirmou que houve um engano na veiculação da notícia e a corrigiu: "os sentenciados da cadeia local estão trabalhando na abertura de covas no cemitério. Por engano dissemos valas, anteontem" (O trabalho..., 12 nov. 1918).

Ao contrário do que ocorrera durante as epidemias de febre amarela na cidade, que foram combatidas sob forte intervenção do Serviço Sanitário Estadual, devido à caótica situação vivida pela capital do estado, o enfrentamento da gripe espanhola em Sorocaba se deu, quase que exclusivamente, por meio dos recursos locais. Para o tratamento dos gripados, foram utilizados o hospital da Santa Casa de Misericórdia, antigos hospitais de isolamento - disponibilizados pela municipalidade - e as sedes de associações filantrópicas e de mútuo socorro, que serviram como enfermarias. Até mesmo os escoteiros locais foram utilizados para transportar medicamentos e auxiliar na notificação de enfermos (Nascimento Filho, 15 jan. 1919).

Em relação às vítimas, na cidade de São Paulo, a maior parte era formada por operários, e muitos deles eram obrigados a continuar trabalhando mesmo estando doentes (Bertucci, 2003, p.128). Em Sorocaba, a situação não era muito diferente. No início de novembro, a fábrica Santa Rosália, devido ao grande aumento do número de gripados entre os operários, foi obrigada a fechar temporariamente: "Quase todos os operários da importante fábrica de tecidos Santa Rosália estão atacados de gripe. Por esse motivo aquele estabelecimento fabril fechou-se temporariamente" (Editorial, 8 nov. 1918).

\section{O caso da fábrica Santa Rosália}

Devido ao recrudescimento da epidemia na cidade, outras fábricas têxteis também foram obrigadas a interromper suas atividades. No dia 15 de novembro, o Cruzeiro do Sul noticiou uma reunião entre industriais e médicos locais para definir a situação das fábricas. A reunião ocorreu no dia 17, no gabinete do prefeito para, segundo o jornal, discutir o tema: "Podem as fábricas reencetar os seus trabalhos já ou não?". Após a exposição da situação epidêmica e da discussão da questão entre os presentes, o prefeito pediu ao experiente médico Álvaro Soares que redigisse um parecer, no qual emitiu a seguinte opinião:

$1^{\circ}$ ) atendendo à característica da epidemia reinante ser a astenia geral do organismo, que muito facilita a invasão de qualquer outra moléstia no atacado, dadas certas condições de meio;

$2^{\circ}$ ) atendendo a que essa mesma astenia do operário vitimado o impossibilita de qualquer serviço;

$3^{\circ}$ ) atendendo à fácil revivescência do gérmen pelo seu microbismo latente, uma vez dada a concorrência das causas circunfusas que favorecem o seu desenvolvimento;

$4^{\circ}$ ) atendendo a que todos os gripados recém-curados e convalescentes não se devem expor a qualquer intempérie sem gravame para si e para a população, pelo recrudescimento provável da moléstia que infelizmente ainda não se acha extinta, mas em plena evolução epidêmica;

Concordam a que o trabalho não deve desde já ser recomeçado e julgam necessário um prazo mínimo de 15 dias para o início do trabalho das fábricas, uma vez que as condições epidêmicas não venham contradizer este asserto (A gripe..., 19 nov. 1918). 
Entre os médicos presentes, estavam João de Almeida Tavares, Odilon Goulart, Gentil Fontes, Eduardo Augusto Pirajá, Ribeiro Neto e Luiz de Almeida. Todos assinaram o parecer redigido por Álvaro Soares, e todos os industriais presentes acataram o documento: "Pela fábrica Votorantim, Pieri Roggieri; pela Co[mpanhia] Nacional de Estamparia, Jorge Kenworthy; pela Co[mpanhia] Fiação e Tecidos N.S. da Ponte, Italo Romano; pela Co[mpanhia] Fiação e Tecidos Santa Maria, Eugenio Mariz" (A gripe..., 19 nov. 1918).

Contudo, Frank Speers, coproprietário da fábrica Santa Rosália, não compareceu à reunião. Procurado pela prefeitura, o industrial declarou "não concordar com a resolução tomada pelos seus colegas, baseando-se na opinião que adrede lhe dera o médico da fábrica Sr. Dr. E. Pirajá" (A gripe..., 19 nov. 1918).

Com essa recusa em acatar a decisão de seus "colegas", a posição do prefeito diante da situação foi:

que comunicaria todas as resoluções ao sr. secretário do Interior e à diretoria do Serviço Sanitário, estabelecendo, caso necessário, um cordão sanitário de modo a isolar inteiramente do resto do município a vila industrial de Santa Rosália, de cujas condições na presente epidemia, se pode avaliar, referindo que só ontem, até a hora em que são escritas estas linhas, registraram-se ali 8 óbitos devidos à gripe (A gripe..., 19 nov. 1918).

Nas edições seguintes, o jornal Cruzeiro do Sul não mencionou se de fato o isolamento ocorreu ou se foi apenas uma ameaça por parte do prefeito, nem tampouco especificou se a fábrica voltou a suspender o trabalho. Entretanto, a partir do episódio, o jornal, que era estreitamente ligado ao poder municipal, passou a noticiar os óbitos causados pela epidemia, destacando na vila operária da fábrica Santa Rosália um alto número de vítimas fatais, por meio de publicações como a do dia 20 de novembro, intitulada "Santa Rosália" (20 nov. 1918):

Na vila industrial de Santa Rosália, desta cidade, o número de gripados, desde o início da epidemia, atingiu a cerca de 900 . O número total de óbitos ali foi de 20, de um mês para cá, sendo que 16 foram por gripe. O sr. F.J. Speers... mantém ali dois hospitais provisórios, a cargo das irmãs beneditinas. O Dr. Eduardo Pirajá, clínico daqueles hospitais, tem com muita dedicação tratado dos operários da Vila.

Já o artigo "Os operários e a influenza", publicado em 23 de novembro de 1918, referiase ao apelo realizado pela Cruz Vermelha Brasileira, em São Paulo, para que os industriais suspendessem os trabalhos em suas fábricas: "com muito acerto agiu a nossa dedicada prefeitura reunindo os Srs. médicos ... e industriais desta cidade ... para serem tomadas as deliberações de que demos notícia terça-feira, em favor dos operários". Em seguida, citava o exemplo das "Indústrias Reunidas Matarazzo" e finalizava, referindo-se ao "Sr. Com[endador] Ermelino Matarazzo" como merecedor dos "mais francos elogios e os nossos mais vivo [sic] votos são de que encontre imitadores" (Os operários..., 23 nov. 1918).

Em outra publicação, de 24 de novembro de 1918, intitulada "A situação dos operários", o jornal noticiou o fato de mais um estabelecimento industrial de São Paulo "acudir ao apelo da Cruz Vermelha em favor dos operários" e continuou:

Nos grandes balanços das empresas industriais o ônus duma quinzena de vencimentos pode ser suportado sem perigo de sua consistência financeira, em benefício de famílias 
inteiras de operários às quais a falta duma quinzena de salários quer dizer miséria, fome e mesmo, às vezes, expulsão da casa que habita (A situação..., 24 nov. 1918).

O fato de o texto mencionar a possível expulsão dos operários de suas casas pela falta ao trabalho é relevante, pois poderia ser uma alusão ao caso da vila operária da fábrica Santa Rosália, em que as moradias dos trabalhadores pertenciam à empresa.

O Almanaque Ilustrado de Sorocaba para 1914, ao enfatizar a importância da fábrica Santa Rosália, descrevia sua vila operária "com a pitoresca casaria uniforme, alinhada em ruas direitas e bem conservadas, ostentando no plano principal a sua grande fábrica de tecidos" (Sorocaba industrial, 2006, p.52). Em seguida, continuava:

De construção moderna e higiênica, a Vila Santa Rosália, que representa em si a eloquência do progresso, progride dia a dia, a fim de abrigar as centenas de operários que impulsionam a indústria com o seu trabalho valioso; aqueles grupos de habitações, modestas ruas que agradam à vista, resumem, juntamente com o edifício da maquinaria, a garantia de uma vida sem grandes preocupações a muitas famílias, às quais a luta pela existência se tornou menos pesada, graças à iniciativa do capitalista benemérito. ... A Vila, anexa a esta [fábrica Santa Rosália], é organizada de 270 casas, escolas públicas, consultório médico, armazém, casa de diversões etc., sendo magnífica a sua iluminação elétrica e perfeito o serviço de encanamento de água (Sorocaba industrial, 2006, p.52-53).

No entanto, "em 1914, a cidade estava muito longe de estar saneada e a rede de água e esgotos, assim como a iluminação elétrica, atendia, e mesmo assim de forma precária, uma parte do núcleo urbano da cidade" (Carvalho, 2008, p.63), enquanto a vila e a fábrica em questão ficavam afastadas um quilômetro da cidade.

Jacob Penteado (citado em Bonadio, 2004, p.222), em suas memórias, reforçou tal situação ao relatar o período em que viveu na mesma vila, nos primeiros anos do século XX:

Em 1900, ano de meu nascimento, a empresa era próspera ... Na encosta da colina, havia várias ruelas de casas rústicas, com telhas vãs, onde, à noite, o vento executava sua lúgubre sinfonia. Nada de instalações sanitárias ou iluminação. Esta era à base de velas ou de lampiões a querosene. Água, só de poço ou do rio próximo. Os moradores, para suas necessidades, recorriam aos urinóis ou, então, iam defecar no mato que cercava as casinholas.

O horário de trabalho era bem amargo. Os operários entravam às cinco da manhã... Tinham quarenta e cinco minutos para almoço, às onze horas. Depois continuavam sua faina, que ia até as oito horas da noite.

No ano referido por Penteado, a cidade ainda não contava com uma rede de água e esgotos. Sua construção só seria iniciada em 1901 e finalizada no ano seguinte, mas, como mencionado acima, funcionou apenas em parte do centro urbano e de forma deficiente.

Além das péssimas condições de moradia e das longas e estafantes jornadas de trabalho, outros problemas eram enfrentados pelos moradores da vila Santa Rosália:

Dentro de vilas fechadas, como a da Fábrica Santa Rosália, localizada em propriedade rural de mesmo nome... os operários estavam quase que totalmente submetidos à autoridade do capitalista: durante o horário de trabalho e fora dele, pois residiam e trabalhavam em sua propriedade, estando por isso sujeitos às regras impostas por ele (Araújo Neto, 2005, p.39). 
O jornal O Operário, em um artigo intitulado "Feudalismo em 1910", denunciava a ausência de liberdade dos moradores das vilas operárias da cidade:

Hoje, que se proclama liberdade em todos os cantos, que leis sobre leis têm sido decretadas para garantia individual, causa pasmo o desleixo das municipalidades, em não legislarem sobre as organizações das vilas operárias... Qualquer capitalista adquire uma área de terreno, junto ou afastado do perímetro da cidade e nela levanta, a seu bel-prazer, não só um estabelecimento de indústria, como também um agrupamento de casas que aluga a seus operários. Nas construções e um [sic] arruamento dessas casas, não vigora fiscalização alguma por parte do governo, embora sejam elas construídas no território do município para residência de homens livres. As ruas não são vias públicas, são circundadas por cerca, valas ou muros, dando passagem um único portão e têm o competente chaveiro [porteiro] (Feudalismo..., 9 jan. 1910, p.1).

Para citar um exemplo concreto desse domínio exercido pelo dono da fábrica sobre os operários residentes na vila, o jornal O Operário, de 12 de setembro de 1909, referia-se à fábrica Votorantim que, por atrasos nos pagamentos, mandou imprimir cartões com valor idêntico ao dos salários em dinheiro, mas que só eram aceitos em um armazém da respectiva vila operária. Em seguida, era mencionado o caso da fábrica Santa Rosália:

Não existem lá os afamados cartões, mais engenhoso é o processo! Só existe o armazém da fábrica e têm os empregados a faculdade de poderem, aqui na cidade, comprar o que quiserem; mas existindo nas proximidades da fábrica um portão e o respectivo porteiro, os que para lá se dirigem conduzindo gêneros, têm forçosamente de se entender com o snr. Porteiro que, de acordo com às instrução [sic] recebidas, nega entrada às carroças que levam as mercadorias... (Os famosos..., 12 set. 1909).

Portanto, compreendendo a situação da vila da fábrica Santa Rosália, pode-se constatar o poder que alguns industriais desfrutavam na cidade. Durante a epidemia de gripe espanhola, esse poder evidenciou-se em diversos aspectos, como na recusa do industrial Frank Speers em acatar as decisões dos médicos sobre o fechamento temporário das fábricas de tecido da cidade, sofrendo até ameaça de sua vila operária ser isolada do resto da cidade por ordem do intendente municipal.

Um caso exemplar desses conflitos reinantes se deu ainda quando o médico Eduardo Pirajá, responsável pelo atendimento na Santa Rosália, ao mesmo tempo que permitiu a continuação do funcionamento da fábrica durante o período crítico da epidemia, assinou, junto aos outros médicos, o parecer de Álvaro Soares em favor do fechamento temporário das fábricas. Essa contradição e a pressão velada exercida pelo Cruzeiro do Sul em seus artigos levaram Eduardo Pirajá a enviar uma carta ao jornal, na qual tentava explicar sua atitude. Segundo o médico, a fábrica Santa Rosália funcionaria:

apenas durante cinco horas por dia, contando com os operários que não tiveram a moléstia e os que já tinham passado o período da convalescença e que estavam em condições de trabalhar e para isso o serviço da fábrica seria iniciado sob minha direta fiscalização como médico oficial do estabelecimento; isto eu declarei na reunião acima referida e se assinei a declaração dos médicos publicada em seu jornal, foi porque considerei que esta visava tão somente aos doentes e aos convalescentes em estado de manifesta fraqueza e que não pudessem trabalhar. Tomei a responsabilidade de 
concordar com o trabalho da fábrica, debaixo das condições acima declaradas, porque não encontrei inconveniência alguma neste trabalho moderado, feito por operários isentos da moléstia e já curados, e por não considerar aglomeração o trabalho de uma fábrica, onde os diversos grupos de operários se dividem por varias seções do serviço, em compartimentos diversos e muito amplos, o esforço físico desses operários seria moderadíssimo atendendo o limitado número de horas que viriam a trabalhar. Esta resolução de fazer trabalhar a fábrica foi sugerida por dois motivos: o primeiro de ordem moral, como um meio de distrair o espírito dos operários e atenuar a atmosfera de desolação e de terror que toda epidemia produz; o segundo era fazer uma espécie de treino, afim de mais tarde os operários poderem suportar o serviço completo da fábrica, dos tempos normais; e de supor que um estabelecimento industrial não possa tirar grandes lucros com um trabalho desfalcado de operários e com a duração de cinco horas apenas por dia (Pirajá, 24 nov. 1918).

Não foram encontrados indícios de que a fábrica Santa Rosália tenha acatado a decisão dos médicos da cidade e mantido a interrupção de sua produção durante a epidemia. Mesmo o intendente municipal, em relatório sobre suas atividades durante o ano de 1918, afirmava não ter tido acesso nem à fábrica e nem ao hospital que teria sido montado na vila operária para atender aos trabalhadores:

O hospital da Santa Rosália não tive ocasião de visitar; ignoro o seu movimento e data de seu fechamento, porque não me foram comunicados, mas soube que se achou sob os cuidados profissionais do Dr. Eduardo Pirajá, médico privado da referida vila, auxiliando-o o farmacêutico Annibal da Costa Dias, que além do seu profissional trabalho durante alguns dias substituiu aquele médico, retido no leito (Nascimento Filho, 15 jan. 1919, p.2).

No dia 30 de novembro, O Cruzeiro do Sul anunciava a reabertura das fábricas de tecidos da cidade para o dia seguinte, junto com notícias sobre o declínio da epidemia. Os óbitos, que em novembro eram noticiados em uma média de oito por dia, continuaram sendo noticiados por todo o mês de dezembro, em número aproximado de um por dia: "Pode-se considerar quase extinta a epidemia da influenza nesta cidade. Não somente são diminutíssimos os casos novos como também tem decrescido o número de óbitos que ontem foram no total de 4" (A influenza, 4 dez. 1918).

A atmosfera de medo ia se dissipando nas páginas jornalísticas, em meio a congratulações mútuas entre autoridades e destacados cidadãos pela atuação durante a epidemia. O Cruzeiro do Sul publicou, no dia 7 de dezembro, um ofício enviado pelo prefeito ao diretor do jornal, Joaquim Firmiano de Camargo Pires, em agradecimento pelos serviços prestados durante o período da epidemia:

A posição nobre assumida pelo vosso criterioso jornal logo que irrompeu aqui a epidemia de gripe, foi mais uma demonstração evidente do interesse que nessa casa merecem todos os assuntos que se dizem diretamente com a vida local, atitude, aliás, que todos os sorocabanos estão habituados a aplaudir (Nascimento Filho, 7 dez. 1918).

Importante destacar que o jornal, apesar de ter sido fundado como um órgão de imprensa da oposição, nesse momento apoiava a situação política local e, como se pode perceber ao analisar a cobertura da gripe espanhola feita por meio de suas páginas, tentou 
minimizar ao máximo a intensidade da epidemia na cidade. O Cruzeiro do Sul, editado pela Tipografia e Papelaria Cruzeiro do Sul, pertencia à família Pires e teve sua primeira edição publicada no dia 12 de junho de 1903. Era dirigido por Joaquim Firmiano de Camargo Pires, filho do coronel Benedito Antonio Pires, um dos mais importantes líderes republicanos, junto com Olivério José do Pilar, desde o final do Império. Nhô Quim, como era conhecido Joaquim Firmiano, junto com seu irmão, o capitão João Clímaco de Camargo Pires, foi ativo participante da política em Sorocaba, tanto compondo o Partido Republicano Paulista (PRP) local como disputando espaço na administração pública (Pinto Jr., 2003, p.90).

O Cruzeiro do Sul também organizou uma "Comissão de socorros" para angariar donativos para os "gripados pobres" que planejava encerrar suas atividades "com chave de ouro" no dia $1^{\circ}$ de janeiro de 1919 em uma missa campal "em ação de graças pela terminação da epidemia de gripe" (Missa..., 10 dez. 1918).

Logo após a passagem de ano, no dia 3 de janeiro de 1919, o jornal, ao se referir à pequena quantidade de pessoas com trajes escuros - em sinal de luto - durante a procissão do dia primeiro, dá uma mostra do impacto causado pela epidemia na cidade:

A epidemia da 'espanhola' produziu mais de trezentas mortes nesta cidade e município. Foi uma rajada de amargura que soprou impiedosa sobre nós durante quarenta dias. Um por cento dos habitantes a morte arrastou ao túmulo. Quinze por cento pelo menos dos sobreviventes deveria ter-se coberto de luto, materialmente que fosse, envergando ternos pretos os homens e vestidos negros as mulheres (Editorial, 3 jan. 1919, p.1; destaque no original).

Entretanto, de acordo com os números oficiais, fornecidos pelo relatório do intendente municipal referente ao ano de 1918, durante a epidemia teriam ocorrido 8.213 casos de gripe e 142 óbitos, em uma cidade com aproximadamente 39 mil habitantes (Nascimento Filho, 15 jan. 1919).

\section{Considerações finais}

Quando a epidemia de gripe espanhola atingiu Sorocaba, em outubro de 1918, a imagem ostentada pela imprensa local sobre a cidade era bem diferente daquela da virada do século. A existência de grandes estabelecimentos fabris ligados à produção têxtil e o crescimento populacional - alimentado, sobretudo, pela imigração - atestavam, na visão das elites locais, a imagem da Manchester Paulista. A epidemia de gripe espanhola ameaçou justamente o símbolo maior do progresso sorocabano à época: as fábricas têxteis. Interrompendo - ainda que temporariamente e sob resistência do proprietário de uma das fábricas - a atividade industrial na cidade, a influenza colocou em xeque um ideal de cidade propagado pela imprensa e expôs a fragilidade das instituições médicas e de saúde pública locais. Sendo assim, o campo da história local pode contribuir para os estudos sobre as epidemias no Brasil - no caso, a de gripe espanhola - ao proporcionar outra perspectiva sobre as crises epidêmicas, redirecionando o foco de análise dos grandes centros para outras localidades, enfatizando suas particularidades. 


\section{REFERÊNCIAS}

A EPIDEMIA.

A epidemia. Cruzeiro do Sul, p.2. 26 out. 1918.

A GRIPE...

A gripe e a situação dos operários. Cruzeiro do Sul, p.2. 19 nov. 1918.

A INFLUENZA.

A influenza. Cruzeiro do Sul, p.1. 4 dez. 1918.

A INFLUENZA.

A influenza. Cruzeiro do Sul, p.1. 10 nov. 1918.

A INFLUENZA.

A influenza. Cruzeiro do Sul, p.2. 6 nov. 1918.

A INFLUENZA...

A influenza na cidade. Cruzeiro do Sul, p.2. 24 out. 1918.

A SITUAÇÃO...

A situação dos operários. Cruzeiro do Sul, p.2. 24 nov. 1918.

ALMEIDA, Aluísio de.

Prof. Dr. José Ribeiro Neto, Sorocabano

Benemérito. Cruzeiro do Sul, p.4. 25 dez. 1964.

ANÚNCIOS.

Anúncios. Cruzeiro do Sul, p.2. 3 jan. 1919.

ARAÚJO NETO, Adalberto C. de.

Sorocaba operária: ensaio sobre o início do movimento operário em Sorocaba, 1897-1920.

Sorocaba: Crearte. 2005.

BERTOLLI FILHO, Claudio.

A gripe espanhola em São Paulo, 1918: epidemia e sociedade. São Paulo: Paz e Terra. 2003.

BERTUCCI, Liane Maria.

Influenza, a medicina enferma: ciência e práticas de cura na época da gripe espanhola em São Paulo. Tese (Doutorado em História) Universidade de Campinas, Campinas. 2003.

BONADIO, Geraldo.

Sorocaba: a cidade industrial (espaço urbano e vida social sob o impacto da atividade fabril). Sorocaba: Edição do Autor. 2004.

BRITO, Nara Azevedo.

"La dansarina": a gripe espanhola e o cotidiano na cidade do Rio de Janeiro. História, Ciências, Saúde-Manguinhos, v.4, n.1, p.11-30. 1997.

CARVALHO, Rogério L.P. de.

Fisionomia da cidade: Sorocaba, cotidiano e desenvolvimento urbano, 1890-1943. Tese (Doutorado em História) - Universidade de São Paulo, São Paulo. 2008.

CARVALHO, Rogério L.P. de.

Aspectos da modernidade em Sorocaba: experiências urbanas e representações, 18901914. Revista de História, n.151, p.221-225. 2004.

CASTRO SANTOS, Luiz Antonio de.

O pensamento sanitarista na Primeira República: uma ideologia de construção da nacionalidade. Dados: Revista de Ciências Sociais, v.28, n.2, p.193210. 1985.

DALL'AVA, João Paulo.

A imprensa jornalística como fonte documental para a história das doenças: as epidemias de febre amarela e de gripe espanhola em Sorocaba. Cadernos de História da Ciência, v.8, n.1, p.91-106. 2012.

EDITORIAL.

Editorial. Cruzeiro do Sul, p.1. 3 jan. 1919.

EDITORIAL.

Editorial. Cruzeiro do Sul, p.2. 8 nov. 1918.

EDLER, Flavio C.

As reformas do ensino médico e a profissionalização da medicina da corte do Rio de Janeiro, 1854-1884.

Dissertação (Mestrado em História Social) Universidade de São Paulo, São Paulo. 1992.

FERREIRA, Luiz Otávio.

João Vicente Torres Homem: descrição da carreira médica no século XIX. Physis: Revista de Saúde Coletiva, v.4, n.1, p.54-77. 1994.

FEUDALISMO...

Feudalismo em 1910. O Operário, p.1. 9 jan. 1910.

GLEZER, Raquel.

Chão de terra e outros ensaios sobre São Paulo. São Paulo: Alameda. 2007.

HOCHMAN, Gilberto.

A era do saneamento: as bases da política de Saúde Pública no Brasil. São Paulo: Hucitec; Anpocs. 1998.

IMPRENSA...

Imprensa sorocabana. Almanaque de Sorocaba para 1903. Sorocaba: Tipografia 15 de Novembro. p.83. (Edição fac-similar). 2007.

MISSA...

Missa de ação de graças. Cruzeiro do Sul, p.2. 10 dez. 1918.

MORFÉTICOS.

Morféticos. O 15 de Novembro, p.2. 2 maio 1897.

MOTA, André.

Notas sobre o sanitarismo de Sorocaba na

Primeira República. Caderno de História, n.2, p.7-14. 2006.

MOTA, André.

Tropeços da medicina bandeirante: medicina paulista entre 1892-1920. São Paulo: Edusp. 2005. 
MOTA, André; BADDINI, Cássia M.

Dilemas revelados e mito desfeito: Sorocaba e a epidemia de febre amarela na República Velha. In: Mota, André; Marinho, Maria Gabriela S.M.C. (Org.). Práticas médicas e de saúde nos municípios paulistas: a história e suas interfaces. São Paulo: USP/Faculdade de Medicina; CDG. 2011.

NASCIMENTO FILHO, Augusto Cesar. Relatório da administração pública de 1918. Cruzeiro do Sul, p.1. 15 jan. 1919.

NASCIMENTO FILHO, Augusto Cesar do. Um ofício. Cruzeiro do Sul, p.2. 7 dez. 1918.

O TRABALHO...

O trabalho dos presos. Cruzeiro do Sul, p.2. 12 nov. 1918.

OS FAMOSOS...

Os famosos cartões. O Operário, p.1. 12 set. 1909.

OS OPERÁRIOS...

Os operários e a influenza. Cruzeiro do Sul, p.2. 23 nov. 1918.

PEREIRA NETO, André de F.

Ser médico no Brasil: o presente no passado. Rio de Janeiro: Editora Fiocruz. 2001.

PINTO JR., Arnaldo.

A invenção da "Manchester Paulista": embates culturais em Sorocaba, 1903-1914. Dissertação (Mestrado em Educação) - Universidade de Campinas, Campinas. 2003.

PIRAJÁ, Eduardo.

Santa Rosália. Cruzeiro do Sul, p.2. 24 nov. 1918.

RIBEIRO NETO, José.

Álvaro Soares. Cruzeiro do Sul, p.3. 27 nov. 1938.

SANTA ROSÁLIA.

Santa Rosália. Cruzeiro do Sul, p.2. 20 nov. 1918.
SCHRAIBER, Lilia Blima.

O médico e seu trabalho: limites da liberdade. São Paulo: Hucitec. 1993.

SEÇÃO LIVRE.

Seção livre. A Voz do Povo, p.2. 22 jan. 1897.

SEÇÃO LIVRE.

Seção livre. O 15 de Novembro, p.2. 21 jan. 1897.

SILVA, Márcia R.B. da.

O laboratório e a República: saúde pública, ensino médico e produção de conhecimento em São Paulo, 1891-1933. Rio de Janeiro: Editora Fiocruz. 2014.

SILVA, Márcia R.B. da.

O texto científico e a atenção médica: Arnaldo Vieira de Carvalho, síntese de um novo profissional. In: Dantes, Maria Amélia M.; Silva, Márcia R.B. da (Org.). Arnaldo Vieira de Carvalho e a história da medicina paulista (1867-1920). Rio de Janeiro: Fundação Miguel de Cervantes. 2012.

SOROCABA INDUSTRIAL.

Sorocaba industrial. Almanaque Ilustrado de Sorocaba para 1914. Sorocaba: Tipografia Werneck. p.38-82 (Edição fac-similar). 2006.

SOUZA, Christiane M.C. de.

A gripe espanhola em Salvador, 1918: cidade de becos e cortiços. História, Ciências, Saúde Manguinhos, v.12, n.1, p.71-99. 2005.

TEIXEIRA, Luiz Antonio. Medo e morte: sobre a epidemia de gripe espanhola de 1918. Rio de Janeiro: Instituto de Medicina Social/Universidade Estadual do Rio de Janeiro. 1993.

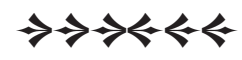

